\title{
ESTUDO DAS PROPRIEDADES MECÂNICAS DO AÇO API X70 PRODUZIDO POR LAMINAÇÃO CONTROLADA
}

\author{
Ronald Lesley Plaut ' \\ Antônio Augusto Gorni ${ }^{2}$ \\ Júlio Toshio Nakashima ${ }^{3}$ \\ Maurício Martins Pereira ${ }^{4}$ \\ José Herbert Dolabela da Silveira ${ }^{5}$
}

\section{Resumo}

A laminação controlada dos aços planos estruturais microligados visa basicamente o refino da microestrutura austenítica ao final da laminação, o qual é transferido para a estrutura ferrítica resultante da sua transformação. Assim consegue-se aumentar simultaneamente a resistência mecânica e a tenacidade do aço. O presente trabalho visa determinar correlações entre as propriedades mecânicas do aço API X70 e o grau de deformação aplicado na fase de acabamento da laminação controlada. Foi observado que reduções de espessura mais pesadas durante a fase de acabamento da laminação controlada pouco afetam a resistência mecânica, mas melhoram significativamente a resistência ao impacto do material, refletindo o refino verificado no tamanho de grão microestrutural.

Palavras-chave: Laminação controlada; Tubos; Propriedades mecânicas; Espessura.

\section{STUDY ABOUT THE MECHANICAL PROPERTIES OF API X70 STEEL PLATE MANUFACTURED BY CONTROLLED ROLLING PROCESS}

\begin{abstract}
The controlled rolling of structural flat micro alloyed steels aims basically to refine the austenitic microstructure at the end of rolling, which fineness is by the final ferritic structure, increasing both mechanical strength and toughness. The present work shows the correlations between mechanical properties of API $5 \mathrm{~L}-\mathrm{X} 70$ steel plates and the strain degree applied during the finishing stage of controlled rolling. It was observed that heavier thickness reductions during the finishing stage has little effect over mechanical strength, but significantly improves toughness, reflecting the refining effect over the microstructural grain size.

Key words: Controlled rolling; Pipes; Mechanical properties; Thickness.

\section{INTRODUÇÃO}

Há algumas décadas a laminação controlada de aços microligados é praticada industrialmente com grande sucesso. Este tratamento termomecânico basicamente toma partido da supressão da recristalização da austenita entre os passes de deformação a quente que ocorrem sob temperaturas relativamente baixas.

Esse fenômeno metalúrgico diminui significativamente o tamanho de grão da austenita e aumenta seu grau de encruamento, dando origem, após sua transformação, a uma microestrutura ferrítica final igualmente refinada, elevando sobremaneira a tenacidade do produto final. ${ }^{(1)}$ A deformação é aplicada em três regiões de temperatura:
\end{abstract}

\footnotetext{
'Sócio da ABM. Professor Associado, Ph.D. Departamento de Engenharia Metalúrgica e de Materiais da EPUSP. Av. Prof. Mello Moraes 2463 , Cep 05508-900, São Paulo, SP, Brasil. E-mail: rlplaut@usp.br.

${ }^{2}$ Sócio da ABM. Engenheiro de Materiais, M.Eng., Dr.Eng., Analista da Operação da Gerência de Suporte Técnico da Laminação a Quente da COSIPA. Estrada de Piaçaguera Km 6, Cep II573-900, Cubatão, SP, Brasil. E-mail: gorni@cosipa.com.br.

${ }^{3}$ Sócio da ABM. Engenheiro Metalurgista, Analista da Operação da Gerência de Suporte Técnico da Laminação a Quente da COSIPA. Estrada de Piaçaguera Km 6, Cep II573-900, Cubatão SP, Brasil. E-mail: juliotoshio@cosipa.com.br. ${ }^{4}$ Sócio da ABM. Engenheiro Metalurgista, MBA, Analista da Operação da Gerência de Suporte Técnico da Laminação a Quente da COSIPA. Estrada de Piaçaguera Km 6, Cep II573-900, Cubatão SP, Brasil. E-mail: mauriciopereira@cosipa.com.br. ${ }^{5}$ Sócio da ABM. Engenheiro Metalurgista, M.Eng., MBA, Gerente de Suporte Técnico da Laminação a Quente da COSIPA. Estrada de Piaçaguera, Km 6, Cep II573-900, Cubatão SP, Brasil. E-mail: herbert.silveira@uol.com.br.
} 
I) Região de altas temperaturas - onde a austenita deformada se recristaliza a cada passe, promovendo refino de grão por ciclos sucessivos de deformação e recristalização;

II) Região de temperaturas intermediárias - onde a austenita é deformada sem que ocorra recristalização entre passes, sofrendo encruamento que se acumula a cada passe e promovendo maior número de sítios disponíveis para a nucleação da ferrita; e

III) Região de temperaturas entre $\mathrm{Ar}_{3}$ e $\mathrm{Ar}_{1}$ - aqui existe uma mistura de austenita e ferrita. A ferrita sofre encruamento, levando a um aumento da resistência do material. A austenita, por outro lado, sofre um encruamento adicional, aumentando ainda mais o número de sítios para nucleação de ferrita com grão ainda mais fino que na região II.

A temperatura de não recristalização, $\left(T_{n n}\right)$, separa a região I da região II e a temperatura de início de transformação austenita/ ferrita $\left(\mathrm{Ar}_{3}\right)$ separa a região II da região III. A determinação destas temperaturas é fundamental para se projetar um esquema de laminação controlada. ${ }^{(2,3)}$

Os precipitados de elementos de micro-liga possuem papéis importantes na laminação controlada, pois controlam o crescimento de grão da austenita no reaquecimento da placa e evitam o crescimento excessivo de grãos recristalizados na região de desbaste. Os precipitados finos que se formam após deformação da austenita na região de acabamento suprimem a ocorrência de recristalização da austenita sob baixas temperaturas na região de não-recristalização. Finalmente, a ocorrência de precipitados finos na transformação da austenita para ferrita aumenta a resistência do material à temperatura ambiente.

Para que o potencial de precipitação dos elementos microligantes seja aproveitado plenamente, é importante que eles se encontrem totalmente solubilizados antes de se iniciar o processo de laminação.

O principal fenômeno que restringe a recristalização entre passes da austenita nos aços microligados é a ocorrência de precipitação de carbonitretos de elementos de liga que paralisa a migração dos contornos da recristalização. Admite-se que $T_{n r}$ (ou $\mathrm{T}_{95 \%}$ ) seja a temperatura onde a precipitação desses carbonitretos passe a afetar a cinética de recristalização, por convenção, quando o tempo necessário para que ocorra recristalização de $95 \%$ do material coincide com o requerido para que ocorra $5 \%$ de precipitação. ${ }^{(4)}$ A Equação I, proposta por Boratto, Barbosa e Santos, (2) determina a $\mathrm{T}_{\mathrm{nr}}$ a partir de resultados obtidos por ensaios de torção a quente com passes múltiplos:

$$
\mathrm{T}_{\mathrm{nr}}=887+464 \% \mathrm{C}+6645 \% \mathrm{Nb}-644 \% \mathrm{Nb}^{0.5}+
$$$$
+732 \% \mathrm{~V}-230 \% \mathrm{~V}^{0.5}+890 \% \mathrm{Ti}+363 \% \mathrm{Al}-357 \% \mathrm{Si} \text {. }
$$

Esta expressão é obtida por uma regressão linear múltipla para uma população de 47 aços microligados diferentes. Os teores da composição química para os quais a equação é válida são: 0,04\% < C < 0, I7\%; $\mathrm{Nb}<0,05 \% ; \mathrm{V}<0,12 \% ; \mathrm{Ti}<0,06 \% ; \mathrm{Al}<0,05 \%$ e $\mathrm{Si}<0,5 \%$. Foi realizado um teste de validade desta equação utilizando-se dos dados de carga e temperatura do processo e, posteriormente, convertidos em resistência média à deformação usando o modelo de Sims ${ }^{(5)}$.
O tamanho de grão da ferrita no final do processo da laminação controlada é função da taxa de nucleação e de crescimento da ferrita na austenita, bem como da composição química do material. $O$ decréscimo de $\mathrm{Ar}_{3}$ diminui a taxa de crescimento da ferrita na austenita. Se a taxa de nucleação não for alterada, tem-se então um decréscimo do tamanho de grão ferrítico final. O cálculo da $\mathrm{Ar}_{3}$ pode ser feito como função da composição química utilizando a Equação 2, desenvolvida por Ouchi: ${ }^{(6)}$

$$
\begin{array}{r}
\mathrm{Ar}_{3}=910-310 \% \mathrm{C}-80 \% \mathrm{Mn}-20 \% \mathrm{Cu}- \\
-15 \% \mathrm{Cr}-55 \% \mathrm{Ni}-80 \% \mathrm{Mo}+0,35(\mathrm{t}-8)
\end{array}
$$

em que t é a espessura da chapa laminada em milímetros, variando de 8 a $30 \mathrm{~mm}$.

As propriedades mecânicas dos aços microligados são resultantes da interação entre os diferentes mecanismos de endurecimento. De forma geral, eles se resumem em: a) endurecimento por solução sólida; b) endurecimento por refino de grão; c) endurecimento por precipitação fina; e d) endurecimento por encruamento da ferrita.

Este trabalho dá enfoque ao mecanismo de endurecimento por refino de grão, que é o mais efetivo nos aços microligados, pois é favorecido pela não-recristalização da austenita durante o processamento termomecânico. ${ }^{(7)} \mathrm{A}$ deformação acumulada na fase de acabamento do processo de laminação controlada contribui diretamente para o refino de grão austenítico e, consequentemente, para o refino de grão ferrítico após transformação de fase. $O$ refino de grão também é favorecido pela precipitação de carbonitretos durante o processamento termomecânico. A precipitação de carbonitretos na austenita sugere que não ocorra recristalização na região III do processamento termomecânico, cujo efeito contribui favoravelmente ao refino da ferrita. ${ }^{(8,9)}$

\section{MATERIAIS E MÉTODOS}

O trabalho experimental foi desenvolvido a partir de duas corridas de um aço de baixo $\mathrm{C}$ microligado ao $\mathrm{NbTiV}$, que foram processadas no Laminador de Chapas Grossas da COSIPA, obtendo-se esboços com dimensões de $14,30 \mathrm{~mm} \times 2.290 \mathrm{~mm}$. O processo termomecânico inicia-se com o desbaste da placa até uma espessura intermediária. Ness, a fase as reduções aplicadas são as mais elevadas possíveis, com o objetivo de "quebrar" a estrutura austenítica grosseira formada durante o reaquecimento através de recristalizações sucessivas. 
Em seguida, interrompe-se a laminação por alguns minutos para que $\circ$ material resfrie até uma temperatura imediatamente abaixo da temperatura de não-recristalização $\left(T_{n r}\right)$, onde se inicia a fase de acabamento, com parte das deformações ocorrendo na região intercrítica. Nesse ínterim, o material não pode sofrer deformação.

Os valores de $\mathrm{T}_{\mathrm{nr}}\left(821^{\circ} \mathrm{C}\right)$ e $\mathrm{Ar}_{3}\left(769^{\circ} \mathrm{C}\right)$ foram calculados previamente por meio das equações empíricas de Boratto e Ouchi, respectivamente, com o objetivo de orientar a definição dos parâmetros do tratamento termomecânico.

Foram testados quatro valores de deformação aplicada na fase de acabamento (52\%, $73 \%, 83 \%$ e $88 \%$ ). Note-se que a redução total placa:chapa foi a mesma para todos os casos. Ou seja, um aumento na deformação aplicada no acabamento sempre implicou numa correspondente diminuição na redução aplicada durante a fase de desbaste.

Os corpos-de-prova foram retirados no meio do esboço laminado, descartando-se assim a influência das pontas frias do esboço, onde reconhecidamente há diferença de propriedades mecânicas. Foram efetuados os seguintes ensaios metalográficos e mecânicos de acordo com a norma API 5L: determinação dos constituintes microestruturais e do tamanho de grão ferrítico; tração; impacto Charpy a $-60,-40,-20,0$ e $25^{\circ} \mathrm{C}$; e Drop Weight Tearing Test a $-60,-40,-20,0$ e $25^{\circ} \mathrm{C}$;.

\section{RESULTADOS}

Para se confirmar os valores preliminares de $\mathrm{T}_{\mathrm{nr}}$ e $\mathrm{Ar}_{3}$, calculados respectivamente pelas equações empíricas de Boratto e Ouchi, a partir da composição química nominal do aço, esses parâmetros foram determinados usando-se gráficos da resistência à deformação a quente versus o inverso da temperatura absoluta levantados a partir dos parâmetros reais da laminação. A Tabela I mostra as temperaturas $\mathrm{T}_{\mathrm{nr}}$ e $\mathrm{Ar}_{3}$ obtidas para as quatro condições testadas.

Observa-se microestrutura predominantemente ferríticaperlítica nas chapas laminadas, conforme mostra a Figura I, com tamanho de grão mais fino e bandeamento mais intenso à medida que se aumentou o grau de deformação no acabamento. O tamanho de grão ferrítico foi determinado pelo método de comparação da norma ASTM EI I2; os resultados obtidos estão mostrados na Tabela 2.

Tabela I. Valores de $\mathrm{T}_{\mathrm{nr}}$ e $\mathrm{Ar}_{3}$ obtidos a partir dos gráficos de resistência à deformação a quente versus o inverso da temperatura

\begin{tabular}{ccc}
\hline $\begin{array}{c}\text { Redução no } \\
\text { Acabamento (\%) }\end{array}$ & $\mathbf{T}_{\mathrm{nr}}\left({ }^{\circ} \mathbf{C}\right)$ & $\mathbf{A r}_{3}\left({ }^{\circ} \mathbf{C}\right)$ \\
\hline 52 & 844 & 774 \\
73 & 863 & 780 \\
83 & 863 & 785 \\
88 & 876 & 782 \\
\hline
\end{tabular}

Tabela 2. Tamanho de grão ferrítico obtido

\begin{tabular}{ccc}
\hline Def Acab (\%) & TG ASTM & TG $(\mu \mathrm{m})$ \\
\hline 52 & 10 & 3,8 \\
73 & 11 & 3,3 \\
83 & 12 & 2,5 \\
88 & 12 & 2,4 \\
\hline
\end{tabular}
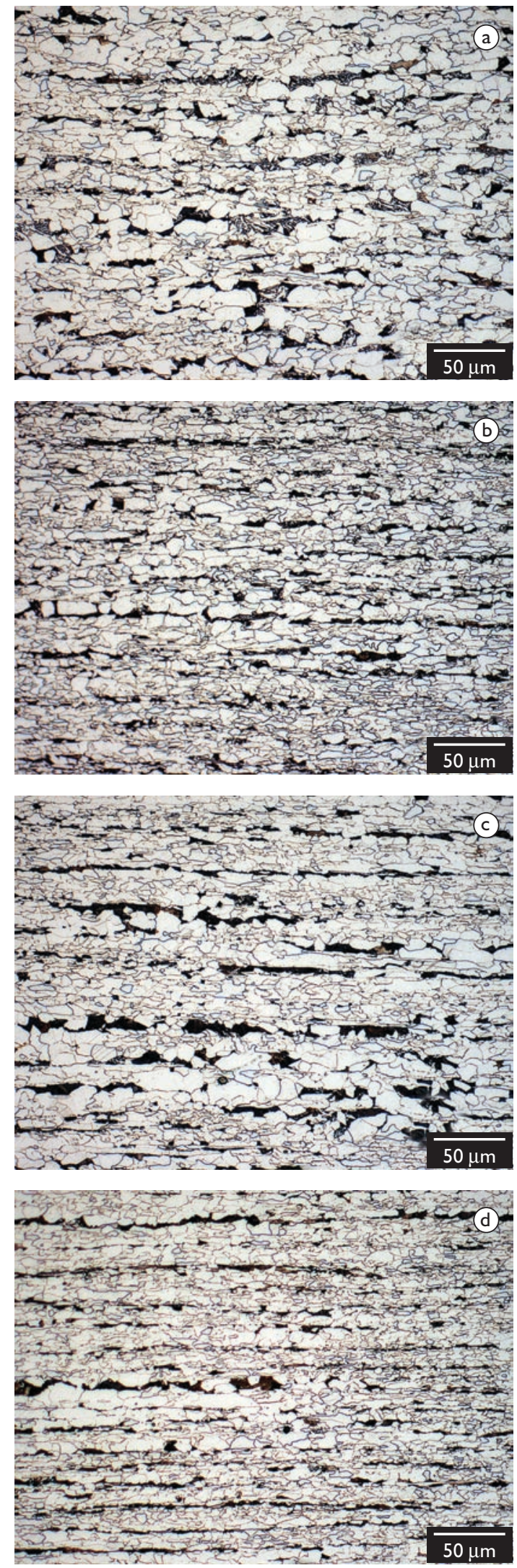

Figura I. Microestruturas observadas na metade da espessura das chapas laminadas com redução na fase de acabamento de a) $52 \%$, b) $73 \%$, c) $83 \%$ e d) $88 \%$. Ataque de Nital $2 \%$, aumento de $350 \mathrm{X}$. 
A Tabela 3 mostra os resultados obtidos pelo ensaio de tração em função dos diferentes graus de deformação aplicados na fase de acabamento da laminação controlada: limites de escoamento (LE) e de resistência (LR), alongamento total (AT) e razão elástica (RE). Já a Tabela 4 mostra os valores de energia absorvida determinados nos ensaios Charpy, e as Tabelas 5 e 6, as frações de área dúctil obtidas nos ensaios Charpy e DWTT, respectivamente. A Figura 2 mostra as superfícies fraturadas dos corpos-de-prova Charpy.

Tabela 3. Resultados das propriedades mecânicas determinadas pelos ensaios de tração

\begin{tabular}{clccc}
\hline Def Acab (\%) & LE (MPa) & LR (MPa) & AT (\%) & RE (\%) \\
\hline 52 & $557 \pm 9$ & $642 \pm 8$ & $35 \pm 2$ & $87 \pm 1$ \\
73 & $576 \pm 15$ & $646 \pm 18$ & $34 \pm 3$ & $89 \pm 1$ \\
83 & $551 \pm 14$ & $623 \pm 14$ & $33 \pm 3$ & $88 \pm 1$ \\
88 & $558 \pm 8$ & $620 \pm 8$ & $34 \pm 3$ & $90 \pm 1$ \\
\hline
\end{tabular}

Tabela 4. Resultados de energia absorvida nos ensaios de impacto Charpy, expressa em joule

\begin{tabular}{ccccc}
\hline Temperatura & \multicolumn{4}{c}{ Grau de deformação no acabamento (\%) } \\
\cline { 2 - 5 }$\left({ }^{\circ} \mathbf{C}\right)$ & $\mathbf{5 2}$ & $\mathbf{7 3}$ & $\mathbf{8 3}$ & $\mathbf{8 8}$ \\
\hline-60 & 41 & 116 & 110 & 146 \\
-40 & 33 & 129 & 164 & 194 \\
-20 & 161 & 185 & 187 & 203 \\
0 & 144 & 162 & 191 & 240 \\
25 & 185 & 194 & 218 & 284 \\
\hline
\end{tabular}

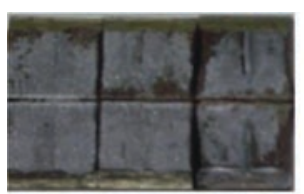

$-60^{\circ} \mathrm{C}$

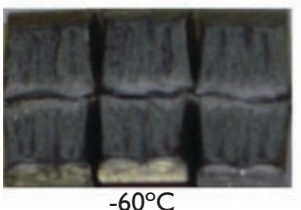

$-60^{\circ} \mathrm{C}$

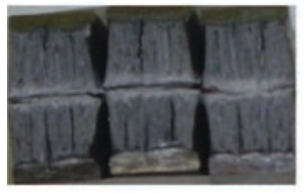

$-60^{\circ} \mathrm{C}$

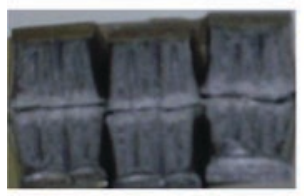

$-60^{\circ} \mathrm{C}$

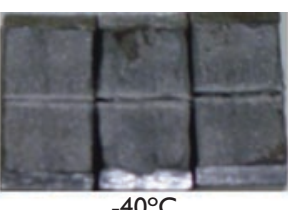

$-40^{\circ} \mathrm{C}$

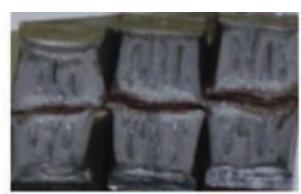

$-20^{\circ} \mathrm{C}$

Pode-se constatar, a partir da Tabela I, que o aumento da deformação na fase de acabamento da laminação controlada eleva a temperatura de não-recristalização. Uma das possíveis explicações para esse fato seria a menor precipitação

Tabela 5. Percentuais de fratura dúctil obtidas nos ensaios de impacto Charpy em função da temperatura do ensaio e da deformação aplicada durante o acabamento

\begin{tabular}{ccccc}
\hline Temperatura & \multicolumn{4}{c}{ Grau de deformação no acabamento (\%) } \\
\cline { 2 - 5 }$\left({ }^{\circ} \mathbf{C}\right)$ & $\mathbf{5 2}$ & $\mathbf{7 3}$ & $\mathbf{8 3}$ & $\mathbf{8 8}$ \\
\hline-60 & 24 & 100 & 100 & 100 \\
-40 & 21 & 100 & 100 & 100 \\
-20 & 100 & 100 & 100 & 100 \\
0 & 100 & 100 & 100 & 100 \\
25 & 100 & 100 & 100 & 100 \\
\hline
\end{tabular}

Tabela 6. Percentuais de fratura dúctil obtidas nos ensaios de impacto DWTT em função da temperatura e dos graus de deformação no acabamento

\begin{tabular}{ccccc}
\hline Temperatura & \multicolumn{5}{c}{ Grau de deformação no acabamento (\%) } \\
\cline { 2 - 5 }$\left({ }^{\circ} \mathbf{C}\right)$ & $\mathbf{5 2}$ & $\mathbf{7 3}$ & $\mathbf{8 3}$ & $\mathbf{8 8}$ \\
\hline-60 & 10 & 57 & 30 & 12 \\
-40 & 60 & 100 & 80 & 35 \\
-20 & 100 & 100 & 100 & 100 \\
0 & 100 & 100 & 100 & 100 \\
20 & 100 & 100 & 100 & 100 \\
\hline
\end{tabular}

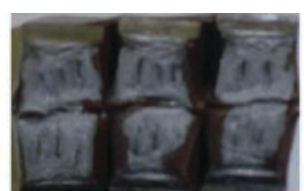

$0^{\circ} \mathrm{C}$

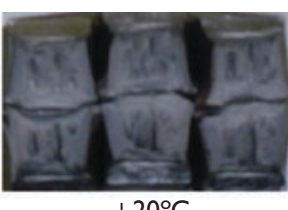

$+20^{\circ} \mathrm{C}$

(a) $52 \%$ de Deformação na Fase de Acabamento.

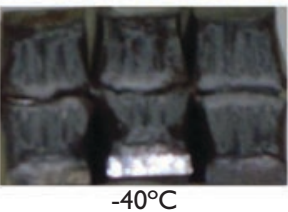

(b) $73 \%$ de Deformação na Fase de Acabamento.

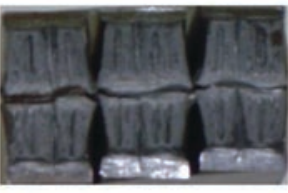

$-40^{\circ} \mathrm{C}$

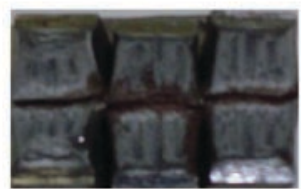

$-20^{\circ} \mathrm{C}$

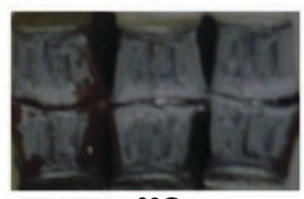

$0^{\circ} \mathrm{C}$

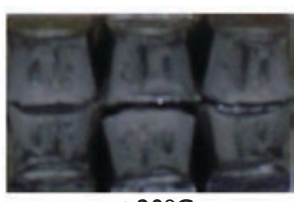

$+20^{\circ} \mathrm{C}$

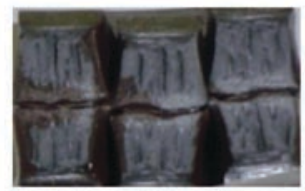

$-20^{\circ} \mathrm{C}$

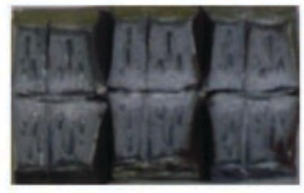

$0^{\circ} \mathrm{C}$

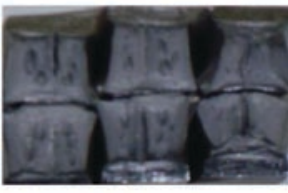

$+20^{\circ} \mathrm{C}$

(c) $83 \%$ de Deformação na Fase de Acabamento.

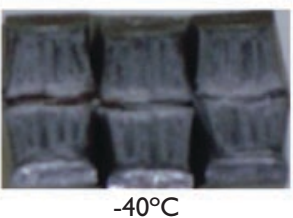

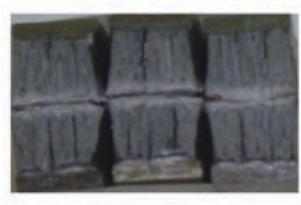

$-20^{\circ} \mathrm{C}$

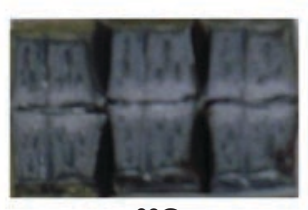

$0^{\circ} \mathrm{C}$

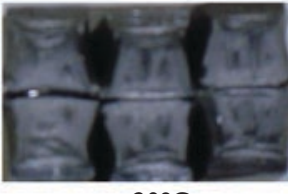

$+20^{\circ} \mathrm{C}$

(d) $88 \%$ de Deformação na Fase de Acabamento.

Figura 2. Aspecto das fraturas nos ensaios de impacto Charpy realizados em diferentes temperaturas em amostras extraídas de chapas submetidas a diversos graus de deformação na fase de acabamento. 
dinâmica de $\mathrm{Nb}(\mathrm{CN})$ durante o desbaste, já que a redução de espessura aplicada durante essa etapa do processo foi menor. Isso contribuiria para aumentar a quantidade de $\mathrm{Nb}$ solúvel na austenita durante a fase de espera, intensificando o efeito retardador desse elemento sobre a recristalização. $\mathrm{A}$ elevação de $\mathrm{Ar}_{3}$, que também é observada com o aumento da deformação aplicada durante o acabamento, poderia ser explicada pelo maior refino de tamanho de grão final proporcionado pela aplicação de maior quantidade de deformação sob baixas temperaturas, intensificando o encruamento da austenita e favorecendo sua rápida transformação em ferrita. De fato, os resultados de tamanho de grão observados na Figura I e na Tabela 2 mostram que, quanto maior é a deformação da fase de acabamento, menor é o tamanho de grão final obtido, confirmando que o aumento do grau de redução aplicada abaixo da $\mathrm{T}_{\mathrm{nr}}$ promove refino microestrutural.

Como indicam os dados da Tabela 3, não são percebidas variações significativas dos resultados de limite de escoamento com a modificação no grau de deformação aplicado durante o acabamento. Por outro lado, percebe-se uma queda média de $20 \mathrm{MPa}$ no limite de resistência ao se aumentar o grau de deformação na fase de acabamento de $52 \%$ para $88 \%$. Tal fato pode ser explicado pelo aumento do gradiente de temperatura entre a superfície e o centro do esboço que ocorre com o aumento da espessura na fase de espera, pois para se acelerar o processo, são aplicados passes de descarepação sobre o esboço durante a espera. Ou seja, a temperatura média do esboço no início da laminação de acabamento deve ter-se elevado à medida que se aumentou o grau de redução aplicado nessa fase do processo. Essa situação é mascarada pelo fato de que a temperatura de referência, medida pelo pirômetro, refere-se à superfície que está sendo intensamente resfriada. O limite de escoamento relativamente inalterado e o declínio do limite de resistência levam a um ligeiro aumento da razão elástica, que varia de $87 \%$ para $90 \%$. Já o alongamento total praticamente não se altera com o aumento no grau de deformação no acabamento, permanecendo em torno de $34 \%$.

Os resultados da Tabela 4 mostram que o aumento do grau de deformação na fase de acabamento conduz a um aumento da energia absorvida pelas chapas durante os ensaios de impacto Charpy. Ou seja, o material mostra-se mais tenaz à medida que a espessura de espera aumenta, fato que pode ser atribuído ao maior refino de grão associado a essa condição de processo, como indica a Tabela 2.

Comparando os resultados de área de fratura dúctil obtidos nos ensaios de impacto Charpy e DWTT, mostrados nas Tabelas 5 e 6, pode-se observar que os melhores resultados são obtidos quando se aplica $73 \%$ de deformação durante a fase de acabamento, um valor intermediário entre os aqui utilizados. Esse valor máximo de área de fratura dúctil pode ser explicado pelo refino de tamanho de grão. $O$ fato dos laminados onde se aplicaram maiores graus de deformação no acabamento ( $83 \%$ e $88 \%$ ) não terem apresentado maiores valores de área de fratura dúctil pode ser atribuído ao aumento do grau de bandeamento observado na microestrutura, como se pode observar na Figura I.

Como mostra a Figura 2, as áreas de fratura dos corposde-prova Charpy apresentam regiões contendo "separações" próximas à região central da chapa, com aspecto semelhante ao verificado na literatura, ${ }^{(10-12)}$ principalmente para ensaios efetuados sob temperaturas abaixo de $-40^{\circ} \mathrm{C}$ e graus de deformação no acabamento acima de $83 \%$. Esta é uma ocorrência comum nos materiais processados por laminação controlada.

\section{CONCLUSÕES}

Com base nos resultados apresentados neste trabalho, pode-se chegar às seguintes conclusões referentes à laminação controlada de chapas grossas grau API X70 com espessura I 4,30 mm, usando-se aço microligado ao NbTiV, aplicando-se diferentes graus de deformação crescentes na fase de acabamento:

I.O limite de escoamento não é afetado significativamente, pois sua variação média não superou $5 \mathrm{MPa}$ para todos os valores de deformação aplicada no acabamento.

2. Há um decréscimo de $20 \mathrm{MPa}$ do limite de resistência para deformações na fase de acabamento acima de $73 \%$. Acredita-se que isso pode ser atribuído à ocorrência de significativo gradiente de temperatura, não mensurado, entre superfície e centro do esboço.

3. Essas evoluções nos valores dos limites de escoamento e resistência contribuem para um leve aumento da razão elástica.

4. Houve um ganho de $83 \%$ na energia absorvida no teste de impacto realizado a temperatura de $-40^{\circ} \mathrm{C}$ quando a deformação na fase de acabamento aumenta de $52 \%$ para $88 \%$.

5. Há uma redução de I,4 $\mu \mathrm{m}$ no tamanho médio de grão quando a deformação na fase de acabamento aumenta de $52 \%$ para $88 \%$.

6. Para deformações no acabamento acima de $73 \%$ observa-se o surgimento de bandeamento mais acentuado de perlita e ferrita, o qual resulta do maior grau de deformação aplicado sob baixa temperatura, já na região intercrítica.

\section{Agradecimentos}

Ao pessoal da Gerência de Qualidade da COSIPA, em especial a Vanessa Pala Branco Rodrigues e a Carlos Augusto Saraiva, pela colaboração neste trabalho. 


\section{REFERÊNCIAS}

I GORNI, A. A. Cálculo da temperatura de não recristalização para aços microligados em função da interação entre a precipitação e recristalização da austenita. REM - Revista Escola de Minas, v. 52, n. I, p. 2 I-25, jan.-mar. 1999.

2 BORATTO, F. J. M.; BARBOSA, R. A. N. M.; SANTOS, D.B. Fundamentos da laminação controlada. Belo Horizonte: Fundação Christiano Otoni, 1989.

3 TANAKA, T. Science and technology of hot rolling process of steel. In: INTERNATIONAL CONFERENCE MICROALLOYING'96, I995, Warrendale. Proceedings... Warrendale: Pittsburgh: ISS, 1995. p. I65-8I.

4 DUTTA, B.; SELLARS, C. M. Effect of composition and process variables on $\mathrm{Nb}(\mathrm{C}, \mathrm{N})$ precipitation in $\mathrm{Nb}$ austenite. Materials Science and Technology, v. 3, n. 3, p. 197-206, Mar. 1987.

5 DIAS, P. C. Estudo das propriedades mecânicas dos aços API X70 na laminação controlada. 2002. Dissertação (Mestrado em Engenharia Metalúrgica) - Universidade Federal de Minas Gerais, 2002. Capítulos 3.2 e 3.3.

$6 \mathrm{OUCHI}, \mathrm{C}$. The effect of hot rolling condition and chemical composition on the onset temperature of gamma-alpha transformation after hot rolling. Transactions of the ISIJ, v. 22, n. 3, p.2I4-22, Mar. 1982.

7 DEARDO, A. J. Metallurgical basis for thermo mechanical processing of microalloyed steels. Iron making and Steelmaking, v. 28, n. 2, p. I38-44, 2001.

8 GALLEGO, J.; KESTENBACH, H. J. Estudo quantitativo dos mecanismos de endurecimento em aços comerciais microligados com vanádio. Revista Matéria, v. I0, n. 3, p.38I-9I, 2005.

9 GORNI, A. A.; REIS, J. S. S.; SILVA, C. N. P.; CAVALCANTI, C. G. Efeito da alteração na espessura de espera durante a laminação controlada sobre os parâmetros microestruturais de chapas grossas navais. In: CONGRESSO ANUAL DA ABM, 50, 1995, São Pedro. Anais... São Paulo: ABM, 1995. 405-2I.

IO SEKINE, H. Deformation in the (austenite plus ferrite) two-phase region. In: TAMURA, I.; SEKINE, H.; TANAKA, T.; OUCHI, C. Thermo mechanical processing of high strength low-alloy steels. London: Butterworths, I988. p.I I0-4.

I I RATNAPULI, R. C.; KATO, H. Efeito de separações nas propriedades de impacto de aços C-Mn-Nb processados por laminação controlada. Metalurgia e Materiais, v. 40, n. 344, p. 445-50, jul. 1986.

I 2 HUNG, C. C. Mechanism of anisotropic lamellar fractures. Metallurgical Transactions A, v. 9A, n. 4, p. 509-5I4, Apr. 1978.

Recebido em: 15/1 I/2008

Aprovado em: 16/08/2009

Proveniente de: SEMINÁRIO DE LAMINAÇÃO - PROCESSOS E PRODUTOS LAMINADOS E REVESTIDOS, 45., 2008, Ipojuca - Porto de Gainhas, PE. São Paulo: ABM, 2008. 